\title{
A Qualitative Study of Parental Knowledge and Perceptions of Human Papillomavirus and Cervical Cancer Prevention in Rural Central Java, Indonesia: Understanding Community Readiness for Prevention Interventions
}

\author{
Belinda Rina Marie Spagnoletti ${ }^{1,2 *}$, Linda Rae Bennett ${ }^{1,2}$, Amirah Ellyza Wahdi ${ }^{2}$, \\ Siswanto Agus Wilopo ${ }^{2,3}$, Christina Alexandra Keenan ${ }^{1}$
}

\begin{abstract}
Background: Cervical cancer (CC) is a leading cause of cancer deaths among Indonesian women. Pilot prevention programs, including human papillomavirus (HPV) vaccination for young adolescent girls, and cervical screening for women, have been implemented. However, many communities are yet to receive these interventions, nor targeted education regarding CC prevention. This study explored community readiness and acceptance of HPV vaccination and CC screening, as well as knowledge and perceptions of HPV and CC, to determine facilitators and barriers to upscaling CC prevention in rural Central Java. Methods: Qualitative data collection in October 2015 consisted of four focus group discussions with married women and men, and 22 semi-structured interviews with married women. All 57 participants, 39 women and 15 men, lived in Purworejo Regency in rural Central Java. Results: Most participants had no knowledge of HPV or the causal link between HPV and CC. However, most participants were supportive of vaccinating their children against HPV. Most participants had heard of cervical cancer, although understandings of symptoms and causes were very poor. Less than half of the women interviewed had undergone CC screening. Multiple barriers to screening were reported, including: a dislike of pelvic exams; embarrassment at being screened by a male doctor; anxiety over the cost; fearing a positive result; and being asymptomatic and thus not perceiving the need for screening. Conclusions: Extensive community education about HPV and CC, targeting women and men, adolescents, health workers and teachers, is crucial to support the introduction of the HPV Demonstration Program and the upscaling of CC screening. Low incomes among rural families underline the need for the HPV vaccine to be provided free within the National Immunization Program, and for CC screening to be free at primary health clinics.
\end{abstract}

Keywords: Human papillomavirus- cervical cancer- reproductive cancer- vaccination- Indonesia- parental acceptance

Asian Pac J Cancer Prev, 20 (8), 2429-2434

\section{Introduction}

Cancers are the cause of $13 \%$ of all mortalities in Indonesia, and cervical cancer (CC) is one of the leading causes of cancer-related deaths among Indonesian women (WHO, 2014; Bruni et al., 2016). More than 93 million Indonesian women are at risk of developing $\mathrm{CC}$, and approximately 21,000 new cases are diagnosed annually, making $\mathrm{CC}$ the second most prevalent female cancer in Indonesia (Bruni et al., 2016; Kosen et al., 2017). The limited research on $\mathrm{CC}$ survival indicates that survival rates are extremely poor, suggesting that it is the most lethal reproductive cancer in Indonesia. In 2004, the five-year survival rate for women with first stage $\mathrm{CC}$ was $50 \%$, for second stage it was $40 \%$, for third stage it was $20 \%$ and for fourth stage it was $0 \%$ (Schellekens et al., 2004).

There is great potential to reduce $\mathrm{CC}$ morbidity and mortality in Indonesia through human papillomavirus (HPV, the etiologic agent for CC) vaccination, cervical screening, and early treatment programs. The imperative of adding HPV vaccination to the National Immunization Program and improving access to CC screening is now unanimously recognised by the Indonesian Government (GOI), the medical profession, and nation-wide cancer advocacy groups (Kosen et al., 2017; Bennett and Spagnoletti, 2019). Progress towards these endeavours includes the development of an HPV Demonstration

${ }^{I}$ Nossal Institute for Global Health, Melbourne School of Population and Global Health, Faculty of Medicine and Dentistry and Health Sciences, The University of Melbourne, Australia, ${ }^{2}$ Center for Reproductive Health, ${ }^{3}$ Department of Biostatistics, Epidemiology and Population Health, Faculty of Medicine, Public Health and Nursing, Gadjah Mada University, Indonesia. *For Correspondence: belinda.spagnoletti@unimelb.edu.au 
Program and a successful application to Gavi, the Vaccine Alliance, for program implementation support (GOI, 2016). The HPV Demonstration Program was initiated in 2017 and piloted as a school-based program in Jakarta and Surabaya, and in two rural districts in Yogyakarta. In 2018 the Program was expanded to include Manado and Makassar. The Program provides free vaccination to girls in primary school, with an initial dose given during grade 5 and the second dose during grade 6 . Purworejo in Central Java was not a target location for the expansion of the HPV Demonstration Program at the time this research was conducted.

As parental consent is required for girls to be vaccinated, research with parents is essential to understanding community readiness for the program. Another study on parental acceptance of HPV vaccination was conducted in 2009, with a quantitative cross-sectional design in five Indonesian provinces $(n=746)$ (Jaspers et al., 2011). Our more recent research complements this earlier study, and offers detailed insights into knowledge gaps and perceptions of HPV and CC, which can only be produced via qualitative research.

Indonesia has developed and piloted a primary health care model for CC prevention that includes detection of pre-cancer cells using visual inspection with diluted acetic acid (VIA), and cryotherapy treatment for women with abnormal cells, or referral to hospital for treatment of more advanced cancer. This pilot was undertaken from 2007 to 2011 in Karawang. Its evaluation is the only prior research on knowledge and perceptions of CC screening and treatment among Indonesian women and men (Kim et al., 2012; 2013). While the Karawang primary care model had not been implemented in Purworejo at the time of our study, staff from the Center for Reproductive Health, Gadjah Mada University had provided free VIA screening for married women via mobile outreach visits in this community for several years prior to the research. The key differences between the pilot evaluation in Karawang and our research is that we looked at HPV vaccination as well as CC screening, and the women and men in our study had not been part of a large-scale CC screening program.

In this qualitative study we aimed to investigate knowledge and perceptions of HPV and CC prevention among married adults with children in Purworejo. Through our data analysis we aimed to identify facilitators and barriers to cancer prevention in this community, and to inform the content of educational materials to increase community readiness for the introduction of HPV vaccination and the upscaling of $\mathrm{CC}$ prevention in rural Central Java.

\section{Materials and Methods}

This article draws on qualitative research undertaken with married women and men in October 2015 in Purworejo Regency, in rural Central Java, Indonesia. While women suffer the embodied realities of $\mathrm{CC}$, both men and women were included to acknowledge men's roles as decision makers in relation to their daughters' reproductive health and their responsibilities as their wives' sexual partners. The methods of data collection we draw on here include focus group discussions (FGDs) with married women and men, and semi-structured interviews with married women. The research tools were designed by LRB and BRMS. The data collection team included BRMS and five Indonesian interviewers.

\section{Recruitment}

Participants were recruited via local government networks of the Center for Reproductive Health's research team in Purworejo. Participants were recruited from Gebang, Gintungan, Sekartejo and Winong Kidul villages. Ethics approval was granted by Gadjah Mada University and all participants gave written informed consent prior to participation. Information about HPV, HPV vaccination, $\mathrm{CC}$ and $\mathrm{CC}$ screening was shared with participants once interviews and FGDs were concluded, to reduce data distortion due to newly acquired knowledge.

\section{Sample}

The total number of study participants was 54 adults (39 women and 15 men). Four FGDs were conducted (17 women and 15 men). Two FGDS were conducted with women from Gebang and Sekartejo villages and two with men from Winong Kidul and Gintungan villages. Women who participated were aged between 28 and 40 years old. Men who participated were aged between 35 to 45 years old. The research team interviewed a further 22 women living in Winong Kidul and Gebang villages. Interview participants were Muslims aged between 22 and 57 years old, with one to five children. All had completed junior high school; more than two-thirds had completed senior high school; and none had received tertiary level education. Most women could not afford private health care and still relied on the primary health system.

\section{Analysis}

Interviews and FGDs were transcribed verbatim, then coded and analysed in NVivo 11. Thematic analysis was undertaken by BRMS and LRB.

\section{Results}

HPV and other sexually transmitted infection (STI) knowledge, risk perception and screening behaviour

Except for one participant whose mother had experienced CC, knowledge of HPV was lacking among all interview and FGD participants, regardless of sex. When asked if they had ever heard of HPV, all participants reported that they had not. Participants' knowledge of STIs other than HPV was also extremely limited. Among women interviewees, perceptions of their risk of contracting HPV or other STIs was low. Sixteen women reported being unconcerned about contracting STIs because they were married and trusted that their husbands were faithful. None made any link between HPV and CC. However, six interviewees did perceive that they were at risk of contracting an STI, although none specified the risk of contracting HPV. Two women understood themselves as potentially at risk because their husbands had been married previously, and four women were concerned as their husbands had spent extended periods living outside 
of Purworejo.

Two of the six women who perceived themselves as at risk had not acted on their risk perception, and had never been screened for HPV or any other STI. One of these women asserted that she would like to be screened, but did not know where to go and feared a positive result. The second woman had used condoms and deemed screening unnecessary because she had never experienced any symptoms. Four of the six women who perceived STI risk had undergone some form of pelvic exam, although only one woman could name the test she had undergone (VIA). However, this woman did not know that it was for CC screening.

\section{CC knowledge}

While detailed knowledge of reproductive cancers was absent among both women and men in this study, all respondents reported having heard of both cervical and breast cancers. Yet, despite all respondents having heard of $\mathrm{CC}$, half of the female interview participants $(\mathrm{n}=11)$ could not accurately name any symptoms, while all male FGD participants could not name any symptoms. Symptoms that were named by interview participants included: irregular vaginal bleeding; abdominal, back, and hip pain; abnormal vaginal discharge; vaginal itchiness; physical changes to the vulva; and weight loss.

Participants' knowledge of CC causes was also limited. In interviews 16 out of 22 women volunteered two or more causes, the most common causes reported were: poor personal hygiene, sexual promiscuity; and having more than one sexual partner. Other causes offered included early marriage, poor diet, exposure to chemicals and genetic factors. Two women reported that a virus causes $\mathrm{CC}$, although they did not make the means of transmission of the virus clear. Women and men who participated in FGDs offered similar perceived causes of $\mathrm{CC}$, most of which were inaccurate.

Only six out of 22 women interviewed offered responses when questioned about $\mathrm{CC}$ prevention. These included: having pelvic exams, using condoms, and avoiding sex with more than one partner. Overall, knowledge of CC was limited and inaccurate among both women and men participants. However, participants of both sexes identified a range of sources where they had obtained some information about CC. These included: the internet, television and radio shows on health, printed health promotion materials available in the primary health care system, and during consultations with midwives, nurses and doctors.

\section{CC screening attitudes and experiences}

Despite only one woman having ever heard of HPV, most interview participants $(n=17)$ were aware of a medical examination that could be performed to screen for CC. Of the 17 interviewees who had heard of CC screening, only seven knew of both tests available in the community: VIA and pap smear. Less than half of the interview participants $(n=7)$ had been screened for $\mathrm{CC}$ and, of those women, several were unsure whether they had experienced VIA or a pap smear. Two women who had undergone screening described the experience as embarrassing. One participant who felt embarrassed to be screened alone explained that she would feel more comfortable if it was part of a community program and her peers were also being screened. Another participant who had a pap smear as part of a community screening program described feeling rushed due to the long queue and receiving a lack of counselling about the procedure.

Women perceived several barriers to CC screening, which included: feeling uncomfortable about pelvic exams; feeling embarrassed to be checked by a male doctor; not knowing where to be tested; not being able to afford testing; fearing a positive result; and being asymptomatic and not perceiving the need for screening. Several women also remarked that CC screening was not yet commonplace in the community due to a poor understanding of risk. The majority of men who participated in FGDs had not heard about screening, and those who had could not provide specific information about what screening involved.

\section{HPV vaccination knowledge and attitudes}

Vaccination in general was regarded as important for disease prevention and immunity by all participants, regardless of gender. In FGDs, vaccination via injection was discussed as a normative practice typically associated with maternal and child health. Trust in the primary health system to provide appropriate vaccinations was also expressed in all FGDs. All women interviewees had received the routine vaccinations administered prior to marriage and during pregnancy, and their children had been vaccinated. Most women and men were supportive of the introduction of HPV vaccination, although some did express reservations. In interviews, 17 women expressed the desire for themselves to be vaccinated, and 20 perceived it to be important for their children to receive the HPV vaccine. Knowledge that the HPV vaccine is strongly recommended prior to sexual debut was not present among any of the women interviewed. Five women expressed conditional support for their children being vaccinated against HPV. These conditions included obtaining permission from their husbands, needing their child to consent to vaccination, or their child not being informed that the vaccine was to protect them from contracting HPV because it is an STI. The third condition was grounded in the fear that if adolescents had knowledge of HPV it could lead to sexual promiscuity. No participants of either gender expressed any concerns that vaccination was haram, forbidden, for any reason according to Islam.

Most interview participants were willing to pay at least a nominal fee for HPV vaccination, although almost half $(n=9)$ would prefer the vaccination to be free. In one FGD with men, participants remarked that if the vaccine was more than Rp. 100.000 it would be prohibitively expensive. Among interview participants, the maximum they were willing to pay was between Rp. 10,000 to 500,000 . At the time of research 1 USD was equal to approximately Rp. 13,500 and the minimum wage in Purworejo was Rp. 1.1 million (BPS Jawa Tengah, 2018).

Asian Pacific Journal of Cancer Prevention, Vol $20 \mathbf{2 4 3 1}$ 


\section{Discussion}

\section{$H P V$ and CC knowledge and perceptions}

Overall, women and men in this study lacked an accurate understanding of both HPV and CC, as well as their causal relationship. All but one participant who had a family member with $\mathrm{CC}$, had not previously heard of HPV, did not know that HPV is a necessary cause of CC, and did not know that HPV is an STI. However, all participants had heard of $\mathrm{CC}$, although none knew that it is caused by an STI. Knowledge of CC symptoms, causes, and prevention was low, incomplete, and interspersed with false understandings. Only half of the interviewees could correctly name CC symptoms, those which may occur at advanced stages, including: irregular vaginal bleeding, abdominal and back pain; abnormal vaginal discharge; and weight loss. Poor or absent knowledge of $\mathrm{CC}$ symptoms has also been observed among women in other low- and middle-income countries (LMICs) with CC high rates, such as Uganda (Mwaka et al., 2015), Nigeria (Ndikom and Ofi, 2012), Malaysia (Wong et al., 2008; 2009), and Mexico (Pelcastre-Villafuerte et al., 2007).

Regarding knowledge of $\mathrm{CC}$ causes, women and men gave a range of responses, some of which were accurate such as having more than one sexual partner, and some of which were false. Both men and women did not hesitate to name and discuss sexual promiscuity as a cause of CC, both within the group context of FGDs and in one-on-one interviews. This finding counters the common assumption that Indonesians are unwilling to discuss sexual behaviour in the context of health, an assumption that has also been critiqued in the context of infertility care in Indonesia (Bennett, 2015). This finding is important because it demonstrates the willingness of this community to engage in frank discussions about how sexual behaviour is linked with HPV and other STIs. This is crucial if behavioural interventions that promote condom use and marital fidelity are also to be promoted. Openness to discussing sexual health could also facilitate the acceptance of providing comprehensive information to women and girls on HPV, other STIs, and the link with CC. This information should be integral to the process of informed consent for those undergoing HPV vaccination and $\mathrm{CC}$ screening and treatment.

Knowledge of CC prevention was even lower than knowledge of its symptoms and causes, indicating that knowledge of HPV as the etiologic agent for CC was virtually absent. Only six out of 22 women volunteered any response to how $\mathrm{CC}$ could be prevented, which included: having pelvic exams; using condoms if having sex with more than one partner; and being vaccinated. Although this shows that knowledge of prevention was low, the fact that this awareness is present points to the feasibility of promoting wider community awareness. Our findings indicate that extensive community education for both women and men on HPV and CC is crucial to support the introduction of the HPV Demonstration Program and the upscaling of CC screening in rural Central Java.

$H P V$ vaccine and CC screening acceptance and barriers Despite participants learning about HPV vaccination for the first time in this study, most women and men asserted that they would support HPV vaccination for their children. High acceptance of HPV vaccination by Indonesian parents was also observed by Jaspers et al., (2011), who reported that $96.1 \%$ of respondents ( $n=717$ ) would accept HPV vaccination of their daughters. Our findings are also similar to levels of parental acceptance reported in Malaysia, where HPV vaccine acceptance was $97.8 \%$ among mothers (Sam et al., 2009). The perception of childhood immunization as a normative practice, and community trust in the primary health care system to provide free immunization for children, also underpinned positive attitudes to the introduction of the HPV vaccination (see also Jaspers et al., 2011). Our research found an absence of any knowledge regarding the potential side effects of HPV vaccination. This knowledge gap should be addressed to ensure that consent to vaccinate is fully informed.

One woman indicated that she would only give consent for her daughter to receive HPV vaccination if her husband also consented. This raised the importance of considering consent processes related to HPV vaccination for girls, and cancer screening and treatment for women. In their study of $\mathrm{CC}$ prevention in Karawang, Kim et al., (2013) noted that the perceived need for a husband's written consent for women to undergo cryotherapy treatment for pre-cancerous lesions was a barrier to some women receiving treatment. Our interviewers did not explicitly probe for participants' attitudes towards husband consent for cancer treatment because our focus was on prevention and vaccination. Further investigation of local understandings of consent is needed to ensure that girls' and women's reproductive rights are protected, and that men and health workers understand the importance of their responsibility to support women in obtaining optimal health care.

Less than half of women participants had been screened for $\mathrm{CC}$, and barriers to screening identified by women included: feeling uncomfortable about undergoing the procedure; feeling embarrassed to be screened by a male doctor; not knowing where to be screened; being concerned about screening costs; fearing a positive result; and being asymptomatic. Jaspers et al., (2011) produced comparable findings on screening barriers. Similarly, Kim et al., (2013) found that women who were asymptomatic perceived no urgency to screen; some avoided screening due to anxiety over a positive diagnosis; and others reported feeling shy to undergo screening.

Concern about screening costs was not apparent in Jaspers et al.,'s (2011) study; as screening was free in that pilot program. However, cost has been identified as a barrier to accessing CC screening in other LMICs, such as South Africa (Francis et al., 2011). Regarding HPV vaccination cost, almost half of our interview respondents said they would prefer a free vaccine, while the rest expressed their willingness to make a nominal payment. Those women and men who were willing to meet the cost of HPV vaccination indicated they would pay up to Rp. 50,000 (USD \$3.50), equivalent to 1.5 days income at minimum wage in Purworejo (based on a six-day work week). This finding is promising, because 
the stated willingness to pay for vaccination demonstrates that it is viewed as a valuable investment towards girls' health within this low income community. However, HPV vaccination currently costs approximately Rp. 1 million per injection in the Indonesian private sector, leaving a substantial gap between what rural families perceive they can afford and the real market cost of the vaccination, which underlines the importance of government subsidization of this vaccine.

Our findings suggest that screening uptake in this community could be improved by responding to women's stated discomfort with the procedure being conducted by male health workers. Employing more women to provide these services is a gender sensitive strategy that would improve health system capacity to meet women's health seeking preferences. Additionally, women's feelings of embarrassment could be addressed by providing greater privacy in clinics, or by allowing a support person to accompany women.

False risk perceptions in relation to $\mathrm{CC}$ have been documented as a barrier to accessing CC screening among women in other LMIC contexts, such as Nigeria (Ndikom and Ofi, 2012), Uganda (Mwaka et al., 2014), and Ethiopia (Birhanu et al., 2012). Similarly, in our study, low risk perceptions among women and men were linked with a lack of understanding of CC as a progressive disease that is initially asymptomatic. For some women, low risk perception was also related to the belief that marriage would protect them from STIs. Unfortunately, the belief that marriage is a protective factor against STIs is not supported by national HIV surveillance data, which indicates that the largest number of new HIV infections have occurred among married housewives, with heterosexual sex with their husbands being the primary mode of transmission (Kemenkes, 2018). It is thus evident that low STI risk perception among married Indonesian women is not representative of the real risks they face. These perceptions need to change for women to adequately protect themselves from HPV and other STIs.

\section{Informing community education on CC prevention}

The findings discussed above illuminate a range of issues and knowledge gaps that should be addressed via community education to ensure readiness for the introduction of HPV vaccination and the upscaling of $\mathrm{CC}$ prevention. Tailored education materials should be developed for men, women, and the adolescents who will receive HPV vaccination. Health workers involved in CC prevention programs also require additional education to ensure they are confident in educating community members about HPV and CC prevention, as many health workers would not have received such content as part of their initial training. Further research is needed to determine the required content for health workers. Knowledge about HPV and CC prevention should also be embedded within the school health program (UKS) curriculum, and teachers who deliver this education should also receive adequate training.

Community education should focus on four interrelated areas: knowledge of HPV, HPV vaccination, CC, and CC screening. HPV education should include: that HPV is the most common STI of the reproductive tract globally; it is the cause of CC and is asymptomatic; it does not have a cure; it can be prevented by vaccination prior to sexual debut; and it can be contracted by anyone who is sexually active, including married women and men.

HPV vaccination education should include: that the vaccine can protect girls from HPV and $\mathrm{CC}$; it is most effective when given before sexual debut; it will involve two injections given 12 months apart; and that side effects may occur, and what action should be taken if side effects are suspected. False perceptions of an association between HPV vaccination and sexual promiscuity should be explicitly addressed, and parents should be informed that there is no evidence that either HPV vaccination or knowledge about STIs has any link with sexual promiscuity (Bennett, 2007). Parents should be informed that HPV vaccination only provides protection against HPV (and potentially genital warts, depending on the vaccine) and that girls who are vaccinated will still be vulnerable to other STIs.

Essential points for $\mathrm{CC}$ education include: that it is a progressive, largely asymptomatic disease that can take many years to reach advanced, symptomatic stages; and it is caused by HPV and can be prevented by vaccination and screening. The community should be informed that many of the commonly identified symptoms of $\mathrm{CC}$, are typically experienced at advanced stages of the disease, and that their presence indicates the need for immediate medical attention.

CC screening education should emphasise: that for women who are already sexually active, screening is the best form of prevention; it can involve either VIA or pap smears; that neither procedure should be painful when conducted properly; and both procedures will be increasingly available for free in the public sector. To allay potential anxiety over the possibility of diagnosis, women should be informed that $\mathrm{CC}$ is highly treatable when diagnosed at early stages. Women should also be informed that treatment at early stages is not prohibitively expensive or as invasive as treatments for later stages of the disease.

Finally, issues of consent for vaccination, screening and treatment should be openly discussed in the community. These conversations should be guided by a reproductive rights framework that acknowledges women's and girl's rights to health and bodily autonomy, and men's responsibilities to promote the health of their wives and daughters. This is not an exhaustive list of what could be covered in the context of community education for CC prevention. However, our suggestions provide a well-informed starting point for developing educational content that responds directly to the observed knowledge, knowledge gaps, and perceptions in this community.

\section{Acknowledgements}

The authors are grateful for the contributions of the interview team, and the support of the health workers and the local research office in Purworejo. This project was funded by the Indonesian Ministry of Education (DIKTI). 


\section{References}

Bennett L (2015). Sexual morality and the silencing of sexual health within Indonesian infertility care. In 'Sex and Sexualities in Contemporary Indonesia: Sexual Politics, Health, Diversity and Representations', Eds Bennett L and Davies S. Routledge, Oxon and New York, pp 148-66.

Bennett L (2007). Zina and the enigma of sex education for Indonesian Muslim youth. Sex Educ, 7, 371-86.

Bennett L, Spagnoletti B (2019). Reproduction: Health: Indonesia. Encyclopedia of Women and Islamic Cultures, Ed. Joseph, S. Brill, Leiden, Supplement 19.

Birhanu Z, Abdissa A, Belachew T, et al (2012). Health seeking behavior for $\mathrm{CC}$ in Ethiopia: a qualitative study. Int $J$ Equity Health, 11, 1-8.

BPS Jawa Tengah, (Statistics of Central Java Province) (2018). Kebutuhan Hidup Layak dan Upah Minimum Kabupaten/ Kota Menurut Kabupaten/Kota di Jawa Tengah Tahun 2000 - 2017 (Rupiah). BPS Jawa Tengah, Semarang.

Bruni L, Barrionuevo-Rosas L, Albero G, et al (2016). Human papillomavirus and related diseases in Indonesia: Summary Report. ICO Information Centre on HPV and Cancer (HPV Information Centre).

Francis SA, Battle-Fisher M, Liverpool J, et al (2011). A qualitative analysis of South African women's knowledge, attitudes, and beliefs about HPV and CC prevention, vaccine awareness and acceptance, and maternal-child communication about sexual health. Vaccine, 29, 8760-5.

GOI (Government of Indonesia) (2016). Application Form for Human Papillomavirus Vaccine (HPV) Demonstration Programme. Indonesia.

Jaspers L, Budiningsih S, Wolterbeek R, Henderson FC, Peters AAW (2011). Parental acceptance of human papillomavirus (HPV) vaccination in Indonesia: A cross-sectional study. Vaccine, 29, 7785-93.

Kemenkes (Ministry of Health) (2018). Laporan situasi perkembangan AIDS and PIMS di Indonesia (2017). Direktorat Jenderelan Pencegahan dan Pengendalian Penyakit, Jakarta.

Kim Y-M, Ati A, Kols A, et al (2012). Influencing women's actions on CC screening and treatment in Karawang District, Indonesia. Asian Pac J Cancer Prev, 13, 2913-21.

Kim Y-M, Lambe FM, Soetikno D, et al (2013). Evaluation of a 5-year CC prevention project in Indonesia: opportunities, issues, and challenges. J Obstet Gynaecol, 39, 1190-9.

Kosen S, Andrijono A, Ocviyanti D, Indriatmi W (2017). The cost-effectiveness of quadrivalent Human Papillomavirus vaccination in Indonesia. Asian Pac J Cancer Prev, 18, 2011-7.

MUI (Majelis Ulama Indonesia) (2018). Fatwa MUI Nomor: 33 Tahun 2018 tentang penggunaan vaksin MR (measles rubella) produk dari SII (Serum Institute of India) untuk imunisasi.

Mwaka AD, Okello ES, Kiguli J, Rutebemberwa E (2014). Understanding CC: an exploration of lay perceptions, beliefs and knowledge about $\mathrm{CC}$ among the Acholi in northern Uganda. BMC Womens Health, 14, 1-9.

Mwaka AD, Okello ES, Wabinga H, Walter FM (2015). Symptomatic presentation with CC in Uganda: a qualitative study assessing the pathways to diagnosis in a low-income country. BMC Womens Health, 15, 1-13.

Ndikom CM, Ofi BA (2012). Awareness, perception and factors affecting utilization of $\mathrm{CC}$ screening services among women in Ibadan, Nigeria: a qualitative study. Reprod Health, 9, $1-10$.

Pelcastre-Villafuerte BE, Tirado-Gómez LL, Mohar-Betancourt A, López-Cervantes M (2007). CC: a qualitative study on subjectivity, family, gender and health services. Reprod Health, 4, 2.

Sam I-C, Wong L-P, Rampal S, et al (2009.) Maternal acceptance of Human Papillomavirus vaccine in Malaysia. J Adolesc Health, 44, 610-2.

Schellekens MC, Dijkman A, Aziz MF, et al (2004). Prevalence of single and multiple HPV types in cervical carcinomas in Jakarta, Indonesia. Gynecol Oncol, 93, 49-53.

WHO (World Health Organization) (2014). Noncommunicable diseases country profiles: Indonesia. WHO, Geneva.

Wong LP, Wong YL, Low WY, Khoo EM, Shuib R (2009). Knowledge and awareness of $\mathrm{CC}$ and screening among Malaysian women who have never had a Pap smear: a qualitative study. Singapore Med J, 50, 49-53.

Wong LP, Wong YL, Low WY, Khoo EM, Shuib R (2008.). CC screening attitudes and beliefs of Malaysian women who have never had a pap smear: A qualitative study. Int J Behav Med, 15, 289-92.

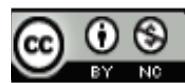

This work is licensed under a Creative Commons AttributionNon Commercial 4.0 International License. 